\title{
A Numerical Research of Heat Transfer in Rectangular Fins with Different Perforations
}

\author{
Kannan C, Sathyabalan P, Ramanathan S
}

\begin{abstract}
Heat Transfer enhancement needs buoyancy force. This is to be achieved by making perforations on fin surfaces. The present paper is a study on the enhancement of heat transfer in terms of density, velocity and temperature with three different perforation geometry (parallel square, inclined square and circular). CFD was used to carry out the study of density variation, velocity and temperature drop among different perforated fins. This type of perforated fin has an improvement in heat transfer rate over its dimensionally equivalent solid fin.
\end{abstract}

Keywords - Heat Transfer, Natural Convection, Perforated rectangular fin. , CFD.

\section{INTRODUCTION}

Extended surfaces are widely used to dissipate the excess amount of heat in engineering systems. The systems like heat exchangers, internal combustion engines, electronic devices, supper heaters etc. should be maintained at an optimum temperature level for its efficient operation without any damage. Under natural convection fins play a vital role in increasing the heat transfer rate. The amount of heat transfer under convection depends upon the surface area of the fin. Basically increasing the surface area increases the size of the equipment leading to systems that are bulky and cost more. Numerous methods were investigated by various researchers to increase the rate of heat transfer with minimum size of the system. Kraus et.al [1] has done a huge literature study on extended surface heat transfer and widely covered all possible orientations of fins. A numerical investigation of a rectangular fin with circular perforations on its surface at constant temperature was carried out by Mohamad et al [2]. Results showed that heat transfer rate increased with perforations compared with solid one. They also compared their results with varying parameters of hole and spacing between perforations. Sane et al. [3] compared free convective heat transfer of horizontal rectangular notched fin with unnotched fin using experimental and CFD analysis. The authors observed that the effect of heat transfer rate is proportional to the heat transfer coefficient and heat flux increases with notch depth.

The effect of different perforation shape and dimension was analyzed by Jassem [4]. The detailed experimental results showed the possibilities of heat loss by the perforated shape geometry under constant surface area. The effect of notch on copper sink material was analyzed by Shivdas et al.

Revised Manuscript Received on September 14, 2019.

Kannan C, Department of Mechanical Engineering, Kumaraguru College of Technology, Coimbatore, Tamilnadu, India.

Sathyabalan P, Department of Mechanical Engineering, Kumaraguru College of Technology, Coimbatore, Tamilnadu, India.(Email: sathyabalan.p.mec@kct.ac.in)

Ramanathan S, Department of Mechanical Engineering, Kumaraguru College of Technology, Coimbatore, Tamilnadu, India.
[5]. They reported that the notched fins had higher heat transfer rates when compared with unnotched ones.

Umesh et al. [6] investigated the effect of perforation diameter, configuration of perforation, fin parameters, heat input and fin angle for enhancement of heat transfer with its solid part. They found an optimal parameter of $12 \mathrm{~mm}$ diameter perforation at an angle of $45^{\circ}$ which maximizes the heat transfer rate up to $32 \%$ and also saves $30 \%$ of mass compared to its solid fin array.

Al-Essa and Al-Hussein [7] analyzed the natural convective heat transfer in horizontal rectangular fins having horizontal square perforations and inclined orientations. This analysis also extends the study of parameters of fins such as fin thickness, perforation dimensions and lateral spacing to enhance the maximum heat dissipation. They found that the inclined orientation was better for small thickness and also parallel perforation for large fin thickness. The author suggests optimum perforation dimensions and spacing to enhance heat transfer.

An attempt is made to study the enhancement of natural convection heat transfer rate in a horizontal rectangular fin with varying perforations.

\section{EXPERIMENTAL}

The fin is modeled as a 100 x $100 \mathrm{~mm}$ plate with thickness $10 \mathrm{~mm}$. The modeling is done for various orientations (Fig.1) and shapes of perforations using GAMBIT software with analysis done using FLUENT software.

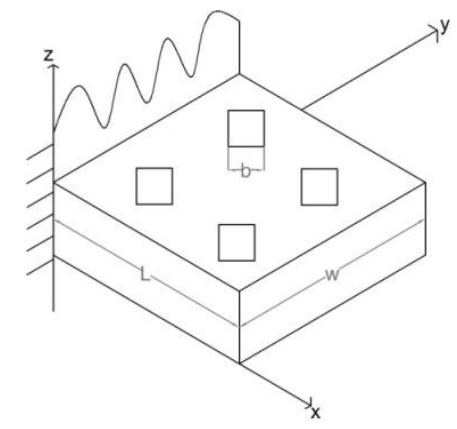

Fig.1. Model

Meshing with triangular surface elements has been necessitated to take care of complicated and skewed surfaces. The surface and volume count for the entire domain are presented in Table 1 
Table 1 Modeling details

\begin{tabular}{|c|c|c|c|}
\hline S.No & Region & Mesh Count & Skewness \\
\hline 1. & Surface & $2,46,248$ & 0.6 \\
\hline 2. & Volume & $7,10,134$ & 0.84 \\
\hline
\end{tabular}

The boundary conditions assumed are as follows

- $\quad$ Fluid is air

- $\quad$ Flow is 3D, turbulent and compressible

- Buoyancy is considered for modeling density variation

- Zero inlet velocity

- $\quad$ Air temperature is $20^{\circ} \mathrm{C}$

- Plate surface is at constant heat flux of $200 \mathrm{~W} / \mathrm{m} 2$

- $\quad$ Far field size as L,W on both sides of the plate

A simple algorithm to couple velocity and pressure has been used. The CFD methodology considered for solvers is presented in Table 2.

Table 2 Solver Methodology

\begin{tabular}{|c|l|c|}
\hline S.No & \multicolumn{1}{|c|}{ Details } & Base Model \\
\hline 1. & Scheme & $\begin{array}{l}\text { Second order upwind } \\
\text { and central difference }\end{array}$ \\
\hline 2. & $\begin{array}{l}\text { Convergence continuity } \\
\& \text { momentum equations }\end{array}$ & less than $10^{-4} \& 10^{-4}$ \\
\hline
\end{tabular}

\section{RESULTS AND DISCUSSION}

Thermal resistance in perforated fin is always greater than a solid fin. Fin temperature and hence surface temperatures are always likewise. The reason for this is sectional area along the fin length and width but the higher diameter perforation lowers the temperature rate. The reason behind this is formation of vortices due to the flow of air stream coming out of the holes. When perforation size increases, the spacing between the perforations decrease. When the spacing between the perforations increase, the vortices become more vigorous. This also enhances other vorticities adjacent leading to better mixing that improves heat transfer. Thus optimum size of hole exists to enhance the heat transfer.

The convection heat transfer rate was analyzed with three parameters like density, velocity and temperature along the surface from the base to fin tip. In this analysis the following parameters : fin thickness, total number of perforation and perforation diameter play an important role.

Considering figure 2 , the lowest density of magnitude $0.96 \mathrm{~kg} / \mathrm{m} 3$ is found near the upper surface which indicates high temperature at the plate and $1.18 \mathrm{~kg} / \mathrm{m} 3$ predicted at the remaining area. Also from the figures 3 and 4, the velocity of air as $1.77 \mathrm{~m} / \mathrm{s}$ above the fin surface and minimum at upper surface of fin. The maximum temperature of $369 \mathrm{~K}$ is found at the plate and in the near vicinity of plate the temperature is found to be $334 \mathrm{~K}$.

Figure 5 shows the density of magnitude $0.998 \mathrm{~kg} / \mathrm{m} 3$ is found near the upper surface which indicates high temperature at the plate $1.18 \mathrm{~kg} / \mathrm{m} 3$ predicted at the remaining area. The velocity was found to be $1.53 \mathrm{~m} / \mathrm{s}$. shown in figure 6 . Figure 7 gives the temperature contour. The maximum temperature of $355 \mathrm{~K}$ is found at the plate and in the near vicinity of plate the temperature is found to be $300 \mathrm{~K}$.
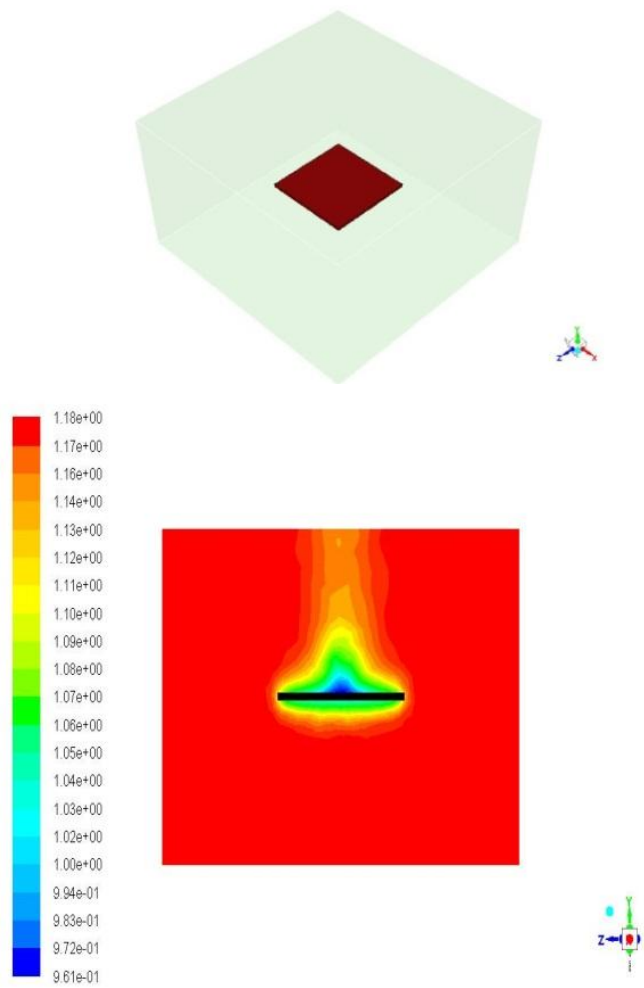

Fig.2. Density distribution plot $(\mathrm{kg} / \mathrm{m} 3)$
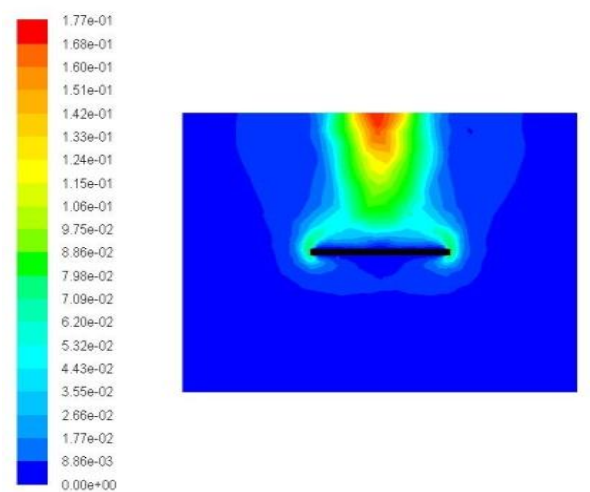

Fig.3 Velocity distribution plot $(\mathrm{m} / \mathrm{s})$

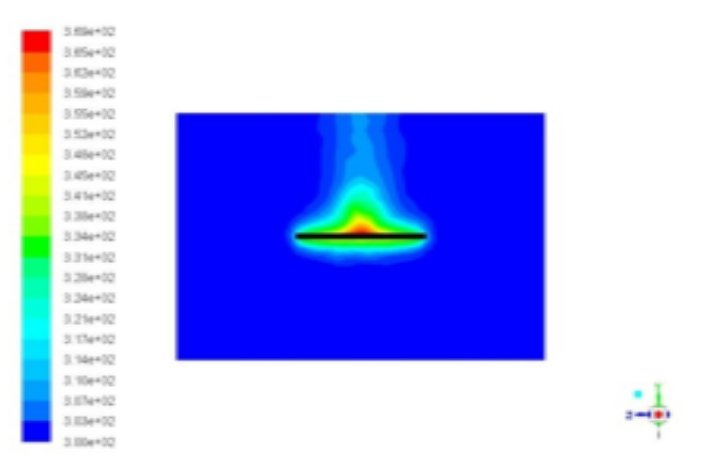

Fig.4. Temperature distribution plot (K) 

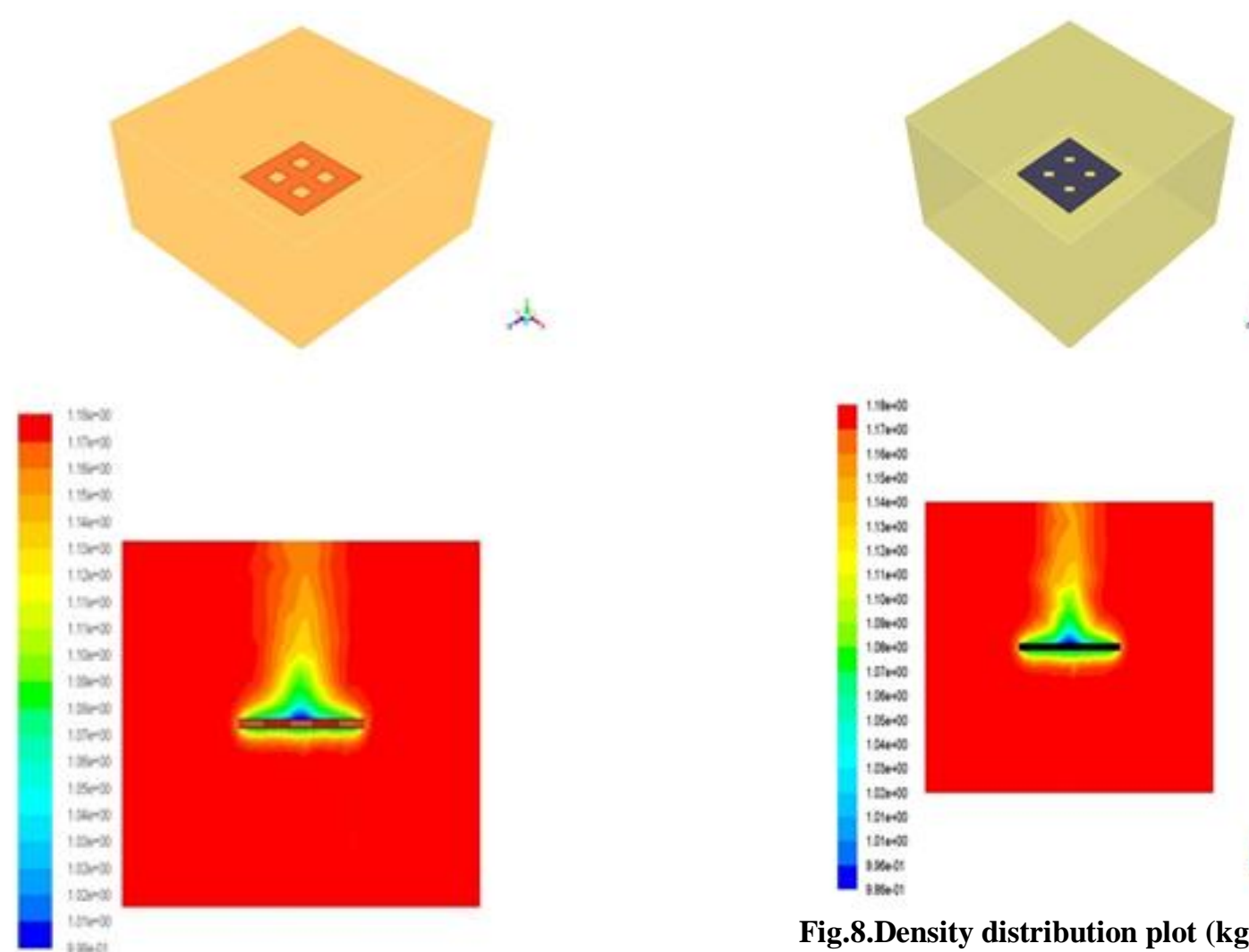

Fig.5. Density distribution plot $(\mathrm{kg} / \mathrm{m3})$

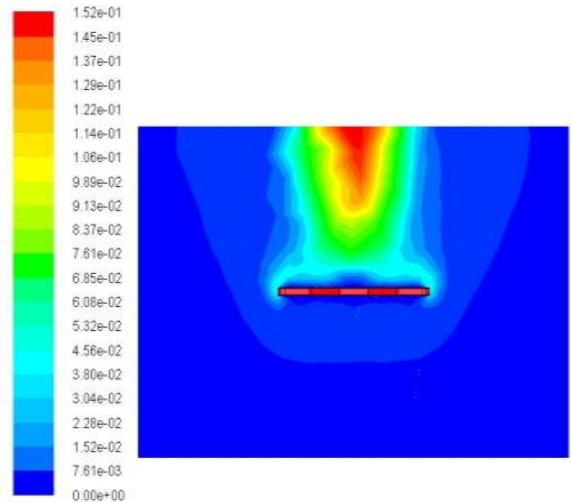

Fig.6. Velocity distribution plot $(\mathrm{m} / \mathrm{s})$

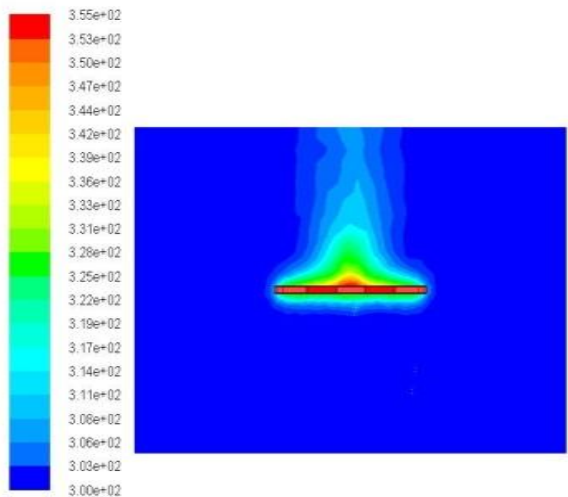

Fig.7. Temperature distribution plot (K)

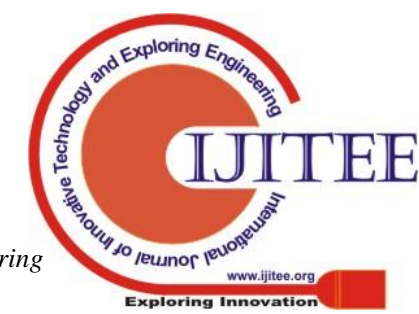


In figure 8 the CFD outcome shows the density of air as $0.91 \mathrm{~kg} / \mathrm{m} 3$ at the flat surface and the velocity is $1.81 \mathrm{~m} / \mathrm{s}$ at upper surface of fin. The temperature of the plate surface at the mid of the plate was $360 \mathrm{~K}$ as shown in figure 10.

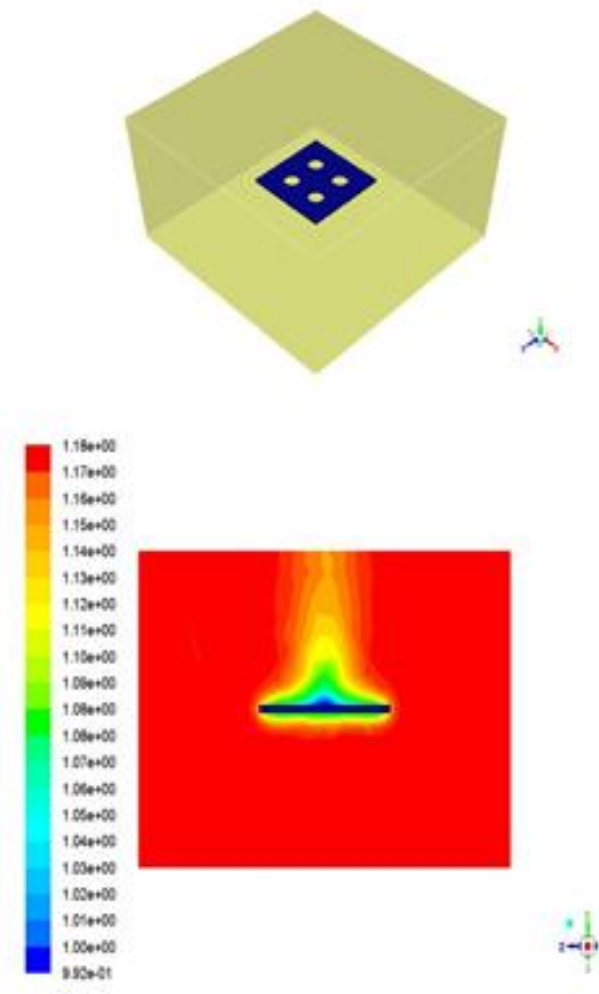

Fig.11. Density distribution plot (kg/m3)

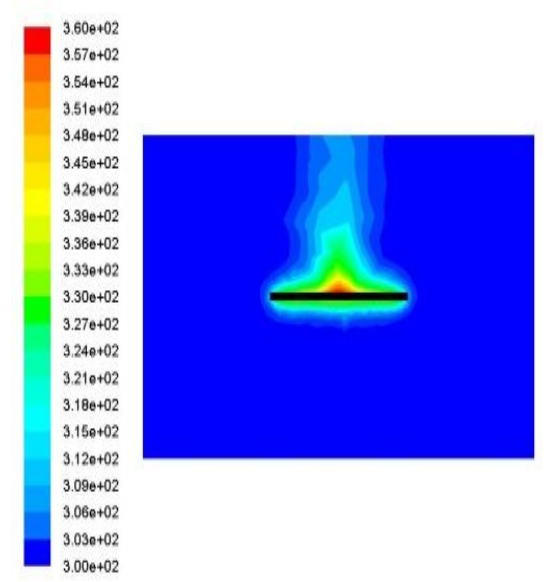

Fig.12. Velocity distribution plot $(\mathrm{m} / \mathrm{s})$

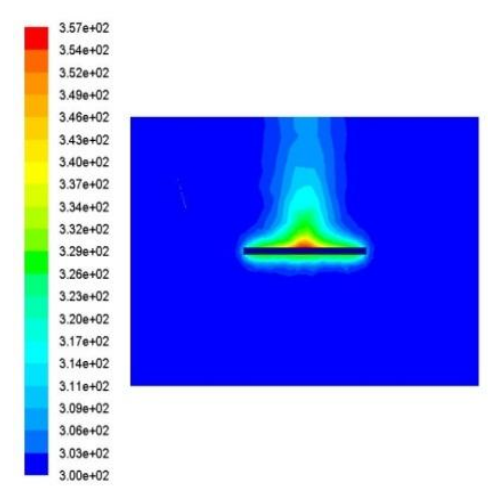

Fig.13. Temperature distribution plot $(\mathbf{K})$
The density of $0.992 \mathrm{~kg} / \mathrm{m} 3$ was predicted at the surface of the plate as shown in figure 12. From the figure it is found that the velocity is $1.61 \mathrm{~m} / \mathrm{s}$ at upper surface of fin . From the figure 13, the contours of temperature was found as $357 \mathrm{~K}$. The comparative results are presented in Table 3.

Table 3 Comparison of Different Perforation

\begin{tabular}{|c|l|c|c|c|c|}
\hline S.No & \multicolumn{1}{|c|}{ Factor } & $\begin{array}{c}\text { Base } \\
\text { Model }\end{array}$ & $\begin{array}{c}\text { Parallel } \\
\text { Square }\end{array}$ & $\begin{array}{c}\text { Inclined } \\
\text { Square }\end{array}$ & Circular \\
\hline 1. & $\begin{array}{c}\text { Density } \\
\left(\mathrm{kg} / \mathrm{m}^{3}\right)\end{array}$ & 0.961 & 0.998 & 0.91 & 0.992 \\
\hline 2. & $\begin{array}{l}\text { Velocity } \\
(\mathrm{m} / \mathrm{s})\end{array}$ & 1.77 & 1.53 & 1.61 & 1.61 \\
\hline 3. & $\begin{array}{l}\text { Temperature } \\
(\mathrm{K})\end{array}$ & 369 & 355 & 360 & 367 \\
\hline
\end{tabular}

Figures 14 and 15 show the static temperature with respect to y co-ordinate for the base and square perforations. The temperature measurement above and below the far field size of plate is shown in the figures. In the base model the temperature varies from $300 \mathrm{~K}$ to $350 \mathrm{~K}$ in the negative side and also it reduces from $370 \mathrm{~K}$ to $310 \mathrm{~K}$. Similarly in the square perforation the temperature varies from $300 \mathrm{~K}$ to 330 $\mathrm{K}$ in the negative $\mathrm{Y}$ co-ordinate side. But in the positive $\mathrm{Y}$ co-ordinate side temperature decreases from $360 \mathrm{~K}$ to 310 $\mathrm{K}$.

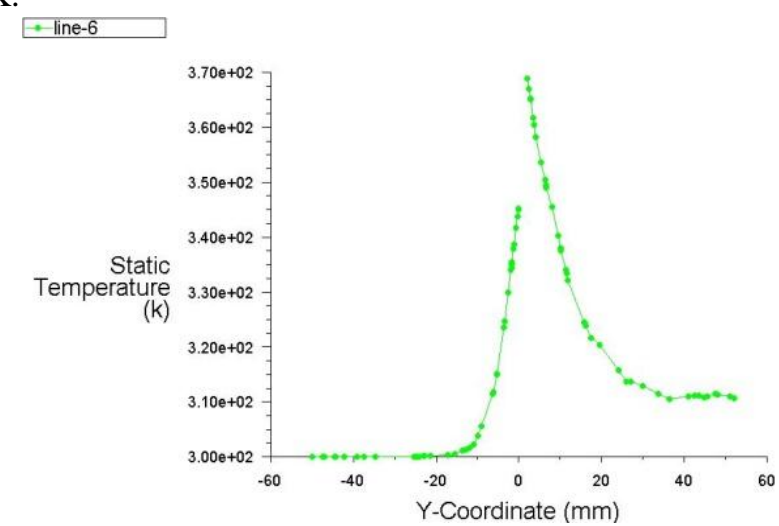

Fig.14.Y Co-ordinate Vs Static Temperature (K) -Base model

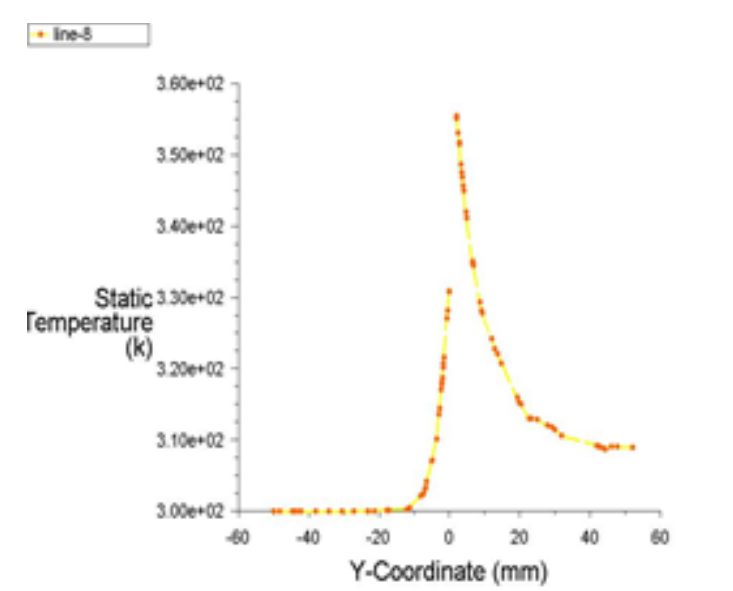

Fig.15. Y Co-ordinate Vs Static Temperature (K) Square perforations 


\section{CONCLUSION}

The drop in temperature along solid fin is higher compared to a perforated fin. The heat dissipation rate can be increased with perforation on the fin surface. The perforation dimension and lateral spacing and number of perforations play a vital role in increasing heat dissipation rate.

CFD analysis has been carried out for three different perforation shapes and compared with the solid part. From this outcome, it was found that the parallel square pattern gives higher heat transfer rate compared to other types.

\section{REFERENCES}

1. A.D.Kraus, A.Aziz, J.Welty, Extended Surface Heat Transfer, John Wiley \& Sons, Inc., 2001.

2. Mohamad I. Al-Widyan and Amjad Al-Shaarawi, Numerical Investigation of Heat Transfer Enhancement for a Perforated fin in Natural Convection, International Journal of Engineering Research and Applications, Vol.2, Issue1, Jan-Feb 2012, 175-184.

3. S.S.Sane, N.K.Sane, G.V. Parishwad, Computational Analysis of Horizontal Rectangular Notched Fin Arrays Dissipating Heat by Natural Convection, 5th European Thermal-Sciences Conference, The Netherlands, 2008.

4. Raaid R. Jassem, Effect the Form of Perforation on the Heat Transfer in the Perforated Fins, Academic Research International, Volume 4, No.3 May 2013, 198-207.

5. Shivdas S. Kharche, Hemant S. Farkade, Heat Transfer Analysis through Fin Array by Using Natural Convection, International Journal of Emerging Technology and Advanced Engineering, Volume 2, Issue 4, April 2012, 595-598.

6. Umesh V. Awasarmol, Ashok T. Pise, An Experimental Investigation of Natural Convection Heat Transfer Enhancement from Perforated Rectangular Fins Array at Different Inclinations, Experimental Thermal and Fluid Science, 68, November 2015, 145-154.

7. Abdullah H. AlEssa, Ayman M. Maqableh and Shatha Ammourah, Enhancement of Natural Convection Heat Transfer from a Fin by Rectangular Perforations with Aspect Ratio of Two, International Journal of Physical Sciences, Volume 4(10), 540-547. 